\title{
Optimized design of a high-power-density PM-assisted synchronous reluctance machine with ferrite magnets for electric vehicles
}

\author{
Xiping LiU, Ya Li, ZhangQi LiU, Tao Ling, Zhenhua Luo \\ School of Electrical Engineering and Automation \\ Jiangxi University of Science and Technology \\ No.86 Hongqi Road, Ganzhou, China \\ e-mail:1y122810@163.com
}

(Received: 14.04.2016, revised: 17.12.2016)

\begin{abstract}
This paper proposes a permanent magnet (PM)-assisted synchronous reluctance machine (PMASynRM) using ferrite magnets with the same power density as rareearth PM synchronous motors employed in Toyota Prius 2010. A suitable rotor structure for high torque density and high power density is discussed with respect to the demagnetization of ferrite magnets, mechanical strength and torque ripple. Some electromagnetic characteristics including torque, output power, loss and efficiency are calculated by 2-D finite element analysis (FEA). The analysis results show that a high power density and high efficiency of PMASynRM are obtained by using ferrite magnets.

Key words: permanent magnet (PM)-assisted synchronous reluctance machine, ferrite magnet, demagnetization, mechanical strength, torque ripple, finite element analysis
\end{abstract}

\section{Introduction}

Recently, a permanent magnet synchronous machine (PMSM) that contains rare-earth permanent magnets (PMs) is popular for its hybrid electrics vehicles (HEVs) and electric vehicles (EVs) [1-2]. Many kinds of PMSMs for traction application are actively studied [3-5]. PMSM, which use rare-earth PMs have some advantages, such as high torque density, high power density, a high power factor, a wide constant power speed range, and high efficiency, etc. However, there is a limitation for rare-earth PMs because of the high price of rare-earth material. Therefore, the electrical machines with less or no rare-earth PMs are required in EVs and HEVs application.

The reluctance motor is one type of electrical machine without PMs. A switched reluctance motor (SRM) has some advantages, such as a simple structure, rotor robustness, the potential to operate at high temperature and torque-speed range, which can be competitive to PMSMs employed in EVs and HEVs [6-10]. Nevertheless, SRM has the problem with a high level of vibration and acoustic noise in general [11-13]. A synchronous reluctance machine (SynRM) 
is also a candidate for a rare-earth-free machine, but its torque density, power density, power factor and efficiency are inferior compared to PMSMs [14-15]. By adding the proper amount of PMs in SynRM, the torque density and power density of a PM-assisted SynRM (PMASynRM) can be improved [16-28]. The total costs of PMASynRM with ferrite magnets can be reduced because some rare-earth materials such as neodymium and dysprosium, needed for automotive applications are not used in this machine.

The rotor structure of PMASynRM must be designed to achieve satisfying high power density, high efficiency, and a wide speed range used in EVs and HEVs. Furthermore, the irreversible demagnetization of the ferrite magnets in cold weather and the mechanical strength of rotor at the maximum speed should be considered [29-32]. Meanwhile, the torque ripple should also be taken into account for the design of PMASynRM based on a finiteelement method (FEM).

In this paper, some characteristics of PMASynRM with ferrite magnets are studied, including the demagnetization behavior, mechanical strength, torque ripple, torque, output power, loss and efficiency.

\section{Target and structure of PMASynRM with ferrite Magnet}

\subsection{Target}

Table 1 shows the specification of an interior permanent magnet synchronous machine (IPMSM) in HEV (Toyota Prius 2010) [33-34], which is called a target IPMSM in this paper. The maximum output power is $60 \mathrm{~kW}$, and its speed varies from 2768 to $13900 \mathrm{r} / \mathrm{min}$ (maximum speed). The outer diameter of the stator is $264 \mathrm{~mm}$, and the stack length is $50 \mathrm{~mm}$. However, the axial length of IPMSM considering the end winding is $108 \mathrm{~mm}$. The volume of the motor core is $5.9 \mathrm{~L}$, which does not include the casing and cooling system. A power density is $10.17 \mathrm{~kW} / \mathrm{L}$. The power density of $10.17 \mathrm{~kW} / \mathrm{L}$ and a maximum speed of $14000 \mathrm{r} / \mathrm{min}$ are the targets of the proposed PMASynRM. The highest efficiency of the target IPMSM is estimated to $95 \%$ for another target of PMASynRM.

Table 1. HEV IPMSM and target

\begin{tabular}{c|c}
\hline Item (Unit) & Value \\
\hline Stator outer diameter $(\mathrm{mm})$ & 264 \\
\hline Stack length $(\mathrm{mm})$ & 50 \\
\hline Machine axial length $(\mathrm{mm})$ & 108 \\
\hline Air gap length $(\mathrm{mm})$ & 0.73 \\
\hline Max. DC side voltage $(\mathrm{V})$ & 650 \\
\hline Max. current $(\mathrm{A})$ & $141^{*}$ \\
\hline Max. output power $(\mathrm{kW})$ & 60 \\
\hline Max. power speed range $(\mathrm{r} / \mathrm{min})$ & $2768-13900^{*}$ \\
\hline Max. torque $(\mathrm{N} \cdot \mathrm{m})$ & 205 \\
\hline
\end{tabular}




\begin{tabular}{c|c}
\hline Max. power density $(\mathrm{kW} / \mathrm{L})$ & 10.17 \\
\hline Max. torque density $(\mathrm{N} \cdot \mathrm{m} / \mathrm{L})$ & 34.67 \\
\hline Max. efficiency $(\%)$ & $95^{*}$ \\
\hline Efficiency at knee point $(\%)$ & $91^{*}$ \\
\hline Winding resistance at $21^{\circ} \mathrm{C}(\Omega)$ & 0.077 \\
\hline Stator turns per coil & 11 \\
\hline Winding type $(\%)$ & distributed \\
\hline Slot fill factor $(\%)$ & $54^{*}$ \\
\hline
\end{tabular}

*Estimated value

The aim of this paper is to investigate a PMASynRM design competitive to the Prius 2010 IPMSM in the point of view of power density, efficiency, a torque-speed region and maximum torque. The proposed PMASynRM with ferrite magnets (Y30BH) are shown in Table 2. The coercive force of ferrite magnet is $232 \mathrm{kA} / \mathrm{m}$ at $20^{\circ} \mathrm{C}$, which is about one-fourth of common rare-earth PMs. Therefore, for achieving high power density, high torque density and high efficiency, a rational rotor structure of PMASynRM should be designed into a multi-layer structure and embed more ferrite magnets by making full use of reluctance torque.

To achieve the maximum torque, the stack length of PMASynRM is one of the most important factors. The number of turns per coil is 8 , which is less than that of Prius 2010 IPMSM. The stator slot depth of PMASynRM is shallower than that of Prius 2010 IPMSM, which results the stator outer diameter of PMASynRM is smaller. As shown in Fig. 1, the stator outer diameter of PMASynRM is set to $245 \mathrm{~mm}$ comparing to the stator outer diameter $264 \mathrm{~mm}$ of Prius 2010 IPMSM. However, the axial length of the motor is $128 \mathrm{~mm}$, and the stack length is $70 \mathrm{~mm}$, so the volume of PMASynRM's core is same as Prius 2010 IPMSM. In addition, the air gap length, maximum dc-side voltage and winding type is the same. Nevertheless, the winding resistance is $0.0646 \Omega$ at $21{ }^{\circ} \mathrm{C}$, which is less than that of Prius 2010 IPMSM.

Table 2. The proposed PMASynRM

\begin{tabular}{c|c}
\hline Item (Unit) & Value \\
\hline Number of poles & 8 \\
\hline Stator outer diameter $(\mathrm{mm})$ & 245 \\
\hline Machine axial length $(\mathrm{mm})$ & 128 \\
\hline Stack length $(\mathrm{mm})$ & 70 \\
\hline Air gap length $(\mathrm{mm})$ & 0.73 \\
\hline Max. DC side voltage $(\mathrm{V})$ & 650 \\
\hline Max. output power $(\mathrm{kW})$ & 60 \\
\hline Max. power speed range $(\mathrm{r} / \mathrm{min})$ & $3000-14000$ \\
\hline Max. torque $(\mathrm{N} \cdot \mathrm{m})$ & 205 \\
\hline Max. efficiency $(\%)$ & 95 \\
\hline PM material & Y30BH \\
\hline
\end{tabular}




\begin{tabular}{c|c} 
Coercive force of PM $(\mathrm{kA} / \mathrm{m})$ & 232 \\
\hline Winding type & distributed \\
\hline Stator turns per coils & 8 \\
\hline Slot fill factor $(\%)$ & 52.3 \\
\hline Winding resistance at $21^{\circ} \mathrm{C}(\Omega)$ & 0.0646 \\
\hline
\end{tabular}

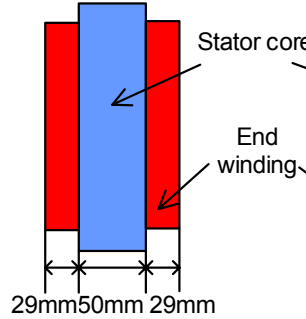

(a)

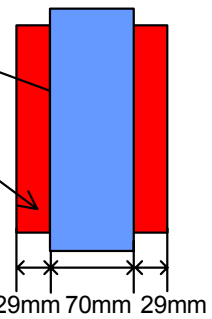

(b)

Fig. 1. Machine axial length: Prius 2010 IPMSM (a); the proposed PMASynRM (b)

\subsection{Structure of PMASynRM with ferrite magnets}

Fig. 2 shows the stator of PMASynRM, which has 48 slots and a distributed winding. In this paper, the optimal rotor structure is discussed for the irreversible demagnetization, torque ripple and mechanical strength at the maximum speed of $14000 \mathrm{r} / \mathrm{min}$.

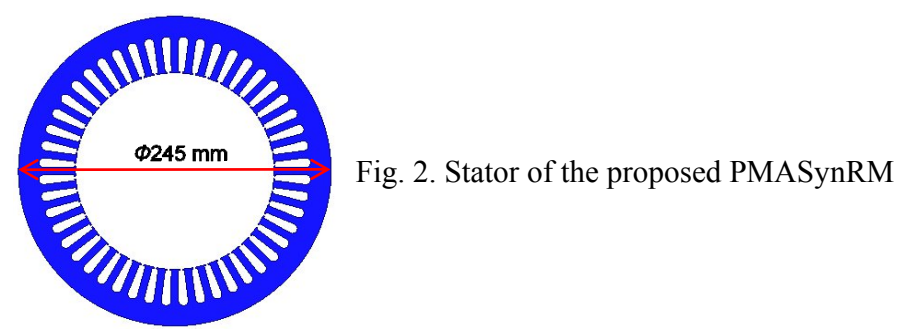

Fig. 3 shows several representative design schemes of a rotor. The rotor structure mainly includes the shape and thickness of ferrite magnets, the shape of flux barriers, the size of central ribs and iron bridges. Fig. 3(a) shows Rotor-A without center ribs, which includes ferrite magnets, flux barriers and iron bridges. Rotor-B is given in Fig. 3(b), which has the center rib to add the mechanical strength of the rotor. Considering the processing of ferrite magnets and irreversible demagnetization, the forth-layer PMs of Rotor-C is designed to a right angle. Moreover, an appropriate flux barrier is designed in center ribs in order to reduce magnetic leakage and achieve sufficient mechanical strength. The same size of PMs and center ribs are adopted for Rotor-C, Rotor-D and Rotor-E, but the shape of flux barriers in the second-layer and third-layer is different. In summary, the rotor structure should be designed by trial and error for decreasing the demagnetization and obtaining sufficient mechanical strength of the rotor. 


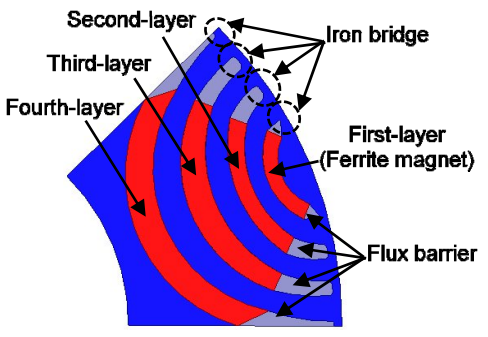

(a)

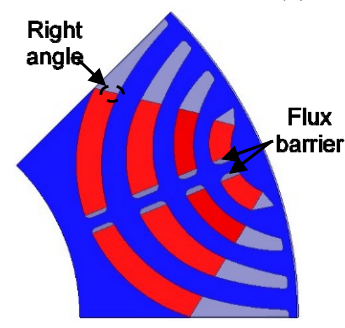

(c)

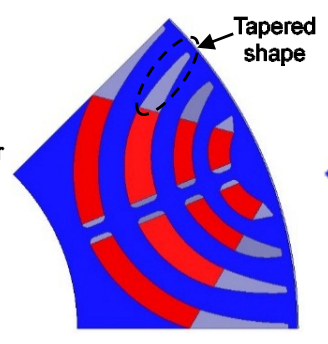

(d)

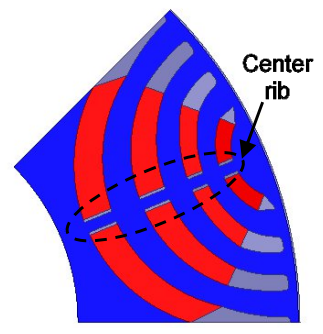

(b)

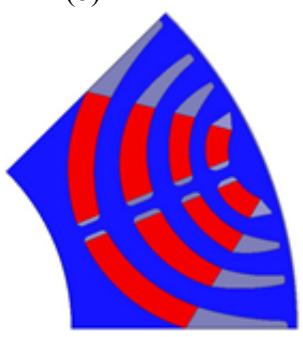

(e)

Fig. 3. Rotor structure of the examined PMASynRM: Rotor-A (a); Rotor-B (b); Rotor-C (c); Rotor-D (d); Rotor-E (e)

\section{Rotor optimization}

\subsection{Evaluation of irreversible demagnetization}

Fig. 4 shows the demagnetization curve of ferrite magnet (Y30BH) used in the proposed PMASynRM. The irreversible demagnetization will occur when the flux density of PMs is lower than the critical flux density at the knee of demagnetization curve. For the purpose of calculating the demagnetization, the flux density of PMs was evaluated. The rate of ireversible demagnetization is defined as the ratio of demagnetizing PMs' area to the total PMs' area, which is called the "demagnetization rate" (DR). In order to assume the severest condition, the temperature of $\mathrm{PMs}$ is set to $-40^{\circ} \mathrm{C}$, the current in the opposite direction of PM's demagnetization magnetomotive force (MMF) is increased to $585 \mathrm{~A}$, which is 1.5 times of the maximum current. The critical flux density of irreversible demagnetization was assumed to be $0.15 \mathrm{~T}$ at $-40^{\circ} \mathrm{C}$ (with margin).

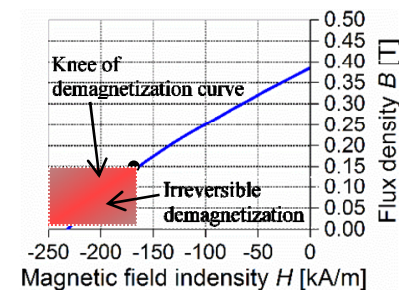

Fig. 4. Demagnetization curve of ferrite magnet (Y30BH) at $-40{ }^{\circ} \mathrm{C}$ 


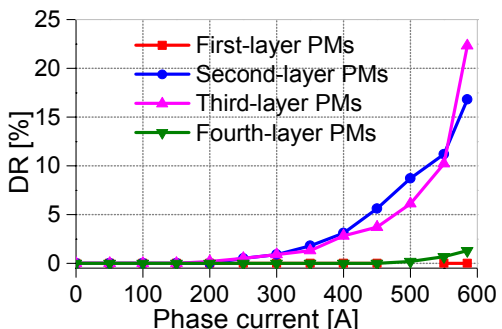

(a)

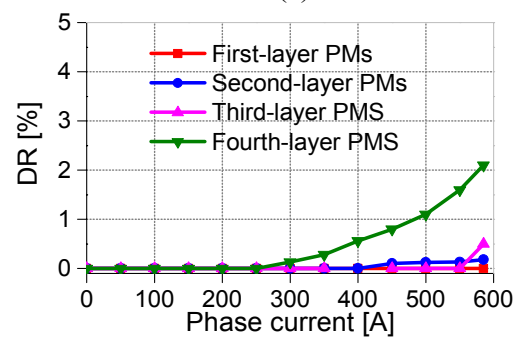

(c)

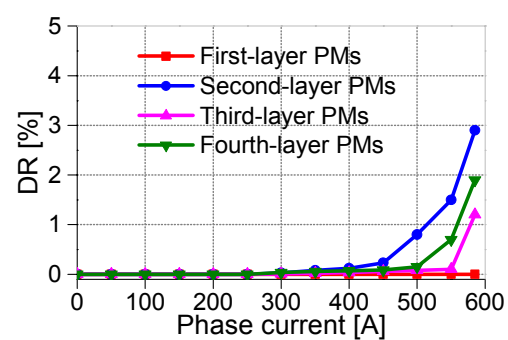

(b)

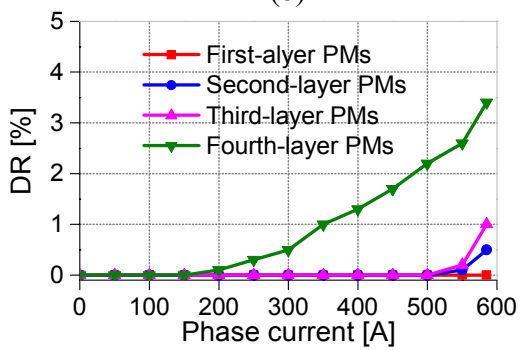

(d)

Fig. 5. Demagnetization rate of PMASynRM at $-40^{\circ} \mathrm{C}$ : Rotor-B (a); Rotor-C (b); Rotor-D (c); Rotor-E (d)

The demagnetization rate at $-40^{\circ} \mathrm{C}$ for some rotors is shown in Fig. 5. The demagnetization of Rotor-A is ignored because it has an obvious problem of mechanical strength. As shown in Fig. 5(a), the demagnetization rate of third-layer ferrite magnet in Rotor-B reaches $22.3 \%$ at $585 \mathrm{~A}$. The demagnetization rate can be improved by changing the rotor structure such as shape, thickness of ferrite magnets and shape of flux barriers. The flux can flow along the iron bridges easily because the reluctance becomes small. As a result, the demagnetization rate of fourth-layer and second-layer ferrite magnets in Rotor- $\mathrm{C}$, Rotor-D and Rotor-E is larger. However, the demagnetization rate is no more than five percent in fourth-layer and second-layer PMs.

Fig. 6 shows the contour plots of flux density at 585 A. It shows that the side part of ferrite magnets in the second-layer and third-layer are irreversible demagnetized in Fig. 6(a). Moreover, the demagnetization also occured in the side part of ferrite magnets in Rotor-C, Rotor-D and Rotor-E, as shown in Figs. 6(b), (c) and (d) respectively.

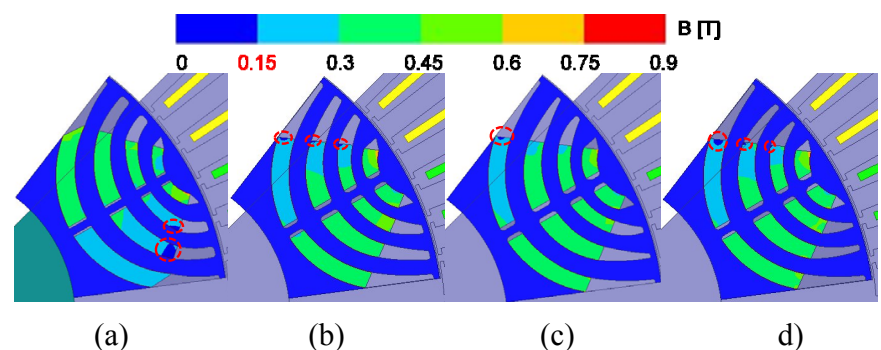

Fig. 6. Contour plots of flux density at 585 A: Rotor-B (a); Rotor-C (b); Rotor-D (c); Rotor-E (d) 
This is because the flux due to the MMF from the stator winding flows primarily through the center ribs and iron bridges. However, the flux also flows over the flux barriers because the thickness of the flux barrier is smaller than that of the ferrite magnet. The result shows that the flux density is too low in the side part of the ferrite magnets, and irreversible demagnetization is occurred. Therefore, the rotor structure such as the shape and thickness of the ferrite magnets, the width of iron bridges and center ribs, the shape of flux barriers were modified to reduce a demagnetization rate by trial and error.

\subsection{Evaluation of mechanical strength}

The mechanical strength of rotor is examined by FEM. Fig. 7 shows the distribution of the von Mises stress at the maximum speed. The ferrite magnets were hidden in those pictures. Rotor-C, Rotor-D and Rotor-E have the same width of center ribs and iron bridges, as the maximum stress area occurred in center ribs and iron bridges. However, it has been confirmed that the proposed rotor structure can withstand the centrifugal force at the maximum speed.

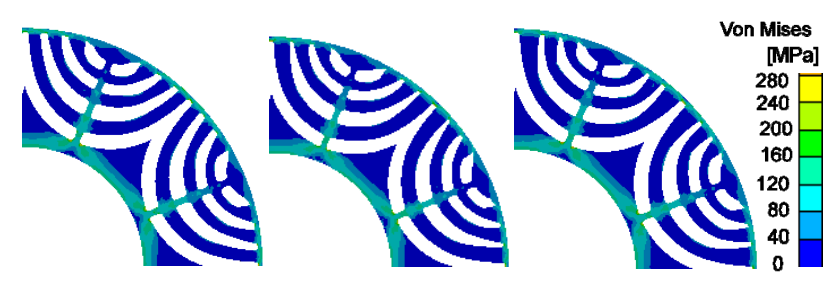

(a)

(b)

(c)

Fig. 7. Von Mises stresses distribution: Rotor-C (a); Rotor-D (b); Rotor-E (c)

\subsection{Torque ripple minimization}

The torque ripple for adopting the different rotor structures is shown in Fig. 8. The torque ripple ratio is defined as ratio of peak-to-peak instantaneous torque to average torque.

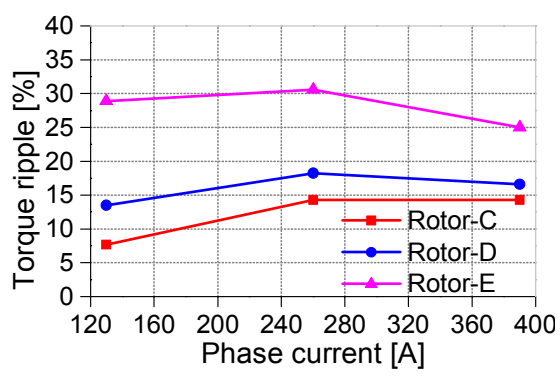

Fig. 8. Torque ripple characteristics

Although a little difference among Rotor-C, Rotor-D and Rotor-E, which is in the shape of flux barriers in the second-layer and third-layer, may cause a great effect on the flux density and reluctance variations around the air gap. Despite a low torque ripple of Rotor-C compared 
to Rotor-D and Rotor-E, the torque ripple is still more than $10 \%$ of the maximum torque. Therefore, the asymmetric flux barrier was used in PMASynRM to reduce the torque ripple [14, 35-40]. Rotor-F and Rotor-G were proposed in Fig. 9. Rotor-G combines the structures of Rotor-C and Rotor-F, and it has an asymmetric flux barrier in the second-layer.

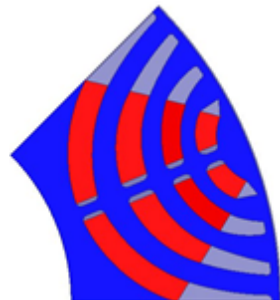

(a)

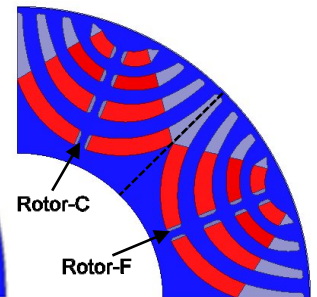

(b)

Fig. 9. Rotor structures with different flux barrier shape: Rotor-F (a); Rotor-G (b)

Current $I_{e m}$ (rms value of phase current) was set to $130,260,390 \mathrm{~A}$ as well as the instantaneous torque characteristics of Rotor-C, Rotor-F and Rotor-G are shown in Fig. 10, and the torque ripple characteristics are given in Fig. 11. Despite of the fact that the torque ripple (only 7.7\%) of Rotor-C is low when $I_{e m}$ is $130 \mathrm{~A}$, it reaches $14.3 \%$ when $I_{e m}$ is 260 and $390 \mathrm{~A}$. The torque ripple of Rotor- $\mathrm{F}$ is $8.5 \%$ at the maximum output torque. However, the torque ripple is more than 10 percent when $I_{e m}$ is 130 and 260 A. Nevertheless, a mutual compensation of the transient torque is realized for Rotor-G by using asymmetric flux barriers, and its torque ripple can be reduced significantly, as shown in Figs. 10(a), (b) and (c).

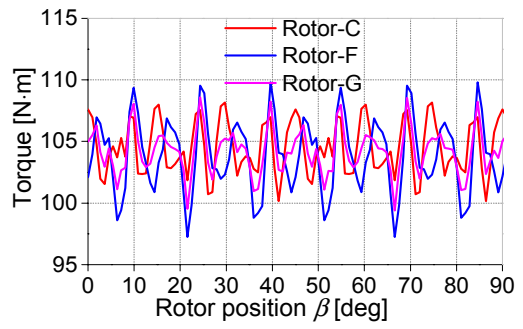

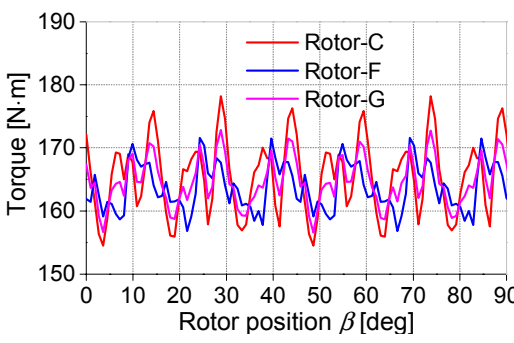

(b) (a)

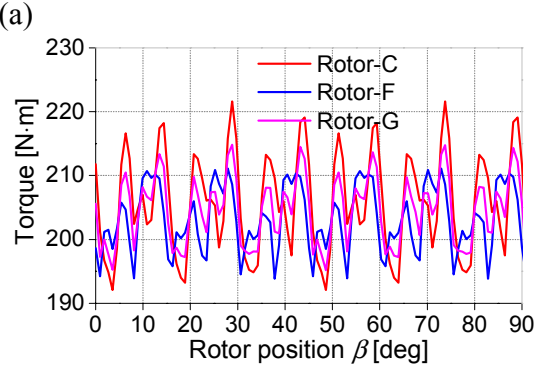

(c)

Fig. 10. Instantaneous torque characteristics: $I_{e m}=130 \mathrm{~A}$ (a); $I_{e m}=260 \mathrm{~A}$ (b); $I_{e m}=390 \mathrm{~A}$ (c) 
Although the torque ripple of PMASynRM increased to $8.8 \%, 9.6 \%$ when $I_{e m}$ was 130 and $390 \mathrm{~A}$, respectively, it is less than $10 \%$. In summary, Rotor-G with asymmetric flux barriers has a great effect on reducing torque ripple. Meanwhile, the average torque of Rotor-G is not reduced by comparing with Rotor-C and Rotor-F, as shown in Fig. 12. This characteristic demonstrates that the proposed PMASynRM has a lower torque ripple by using asymmetric flux barriers, which is competitive to theToyota Prius 2010 IPMSM.

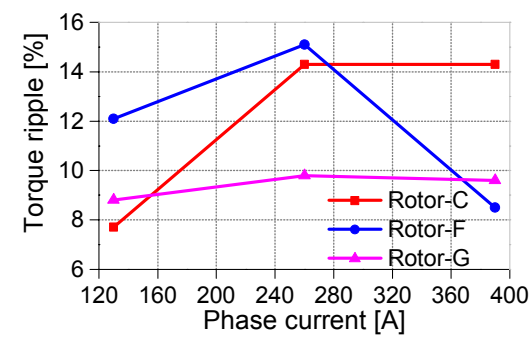

Fig. 11. Torque ripple characteristics

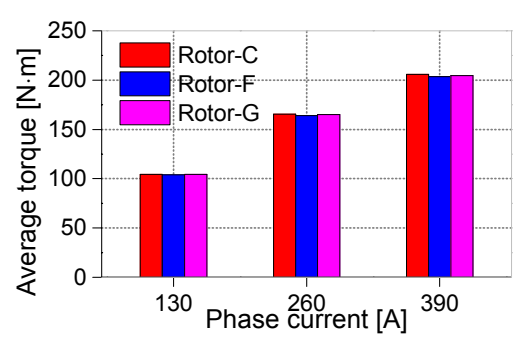

Fig. 12. Average torque

\section{Performance evaluation}

\subsection{Torque and output power versus speed}

Because the dc-side voltage is assumed to be $650 \mathrm{~V}$, the voltage limit $V_{e m}$ (rms value of line-to-line voltage) was set to $450 \mathrm{~V}$. The current limit $I_{e m}$ was set to 130,260 and $390 \mathrm{~A}$. It is noted that $I_{e}$ becomes smaller than $I_{e m}$ when the maximum torque per ampere (MTPA) control is applied during flux-weakening operation, and $I_{e m}$ is a ceiling value of current.

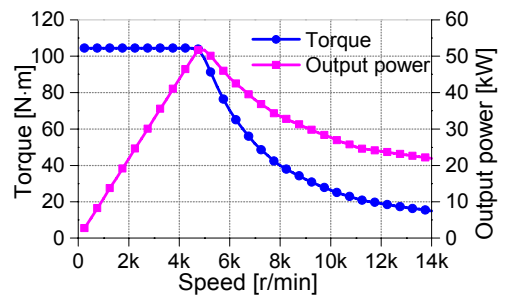

(a)

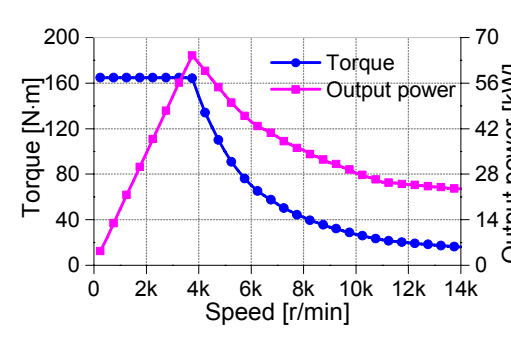

(b)

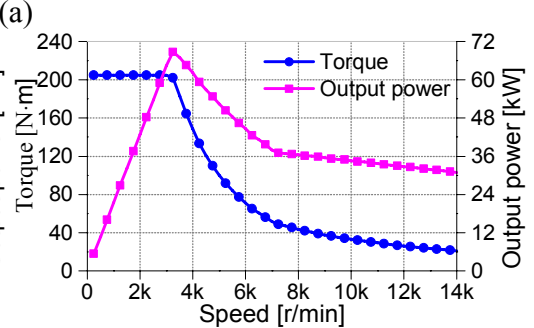

(c)

Fig. 13. Torque and output power versus speed: $I_{e m}=130 \mathrm{~A} \mathrm{(a);} I_{e m}=260 \mathrm{~A} \mathrm{(b);} I_{e m}=390 \mathrm{~A}$ (c) 
The torque and output power versus speed relationships are shown in Fig. 13. With the proposed rotor structure, the maximum output power is $49.2 \mathrm{~kW}$ at $4500 \mathrm{r} / \mathrm{min}$ in Fig. 13(a), and constant torque is $104.4 \mathrm{~N} \cdot \mathrm{m}$. When $I_{e m}$ was set to $260 \mathrm{~A}$, the maximum output power reaches to $64.4 \mathrm{~kW}$ at $3750 \mathrm{r} / \mathrm{min}$. However, the peak torque is only $164.8 \mathrm{~N} \cdot \mathrm{m}$, which is less than the target of the maximum output torque $205 \mathrm{~N} \cdot \mathrm{m}$, as shown in Fig. 13(b). Fig. 13(c) shows that the maximum output power is $68.7 \mathrm{~kW}$ at $3250 \mathrm{r} / \mathrm{min}$, which reaches the target maximum output power. Meanwhile, the maximum torque is $204.8 \mathrm{~N} \cdot \mathrm{m}$ when $I_{e m}$ is $390 \mathrm{~A}$, which is very close to the target torque. It indicates that a reasonable design of the rotor structure in the proposed PMASynRM could achieve a high power density and high torque density by using low-cost ferrite magnets.

\subsection{Loss and efficiency characteristics}

The loss and efficiency versus speed relationships is given in Fig. 14. The iron loss, copper loss and efficiency were calculated by the following equations

$$
\begin{gathered}
W_{i}=W_{h}+W_{e}, \\
W_{c}=3 R_{a} I_{e}^{2}, \\
\eta=\frac{\omega T-W_{i}}{\omega T+W_{c}} \times 100 \%,
\end{gathered}
$$

where $W_{h}$ is the hysteresis loss [W], $W_{e}$ is the eddy current loss [W], $W_{i}$ is the iron loss [W], $W_{c}$ is the copper loss [W], $R_{a}$ is the armature winding resistance [ $\left.\Omega\right], I_{e}$ is the RMS value of phase current $[\mathrm{A}], \eta$ is the efficiency [\%], $T$ is the torque $[\mathrm{N} \cdot \mathrm{m}]$, and $\omega$ is the mechanical angular velocity $[\mathrm{rad} / \mathrm{s}]$.

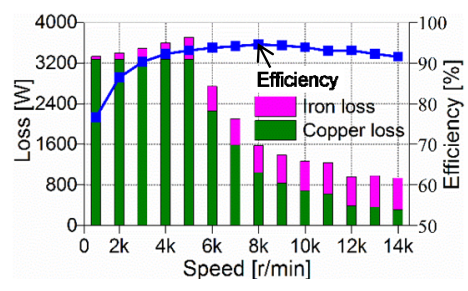

(a)

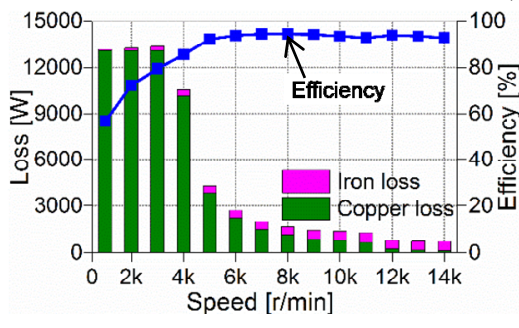

(b)

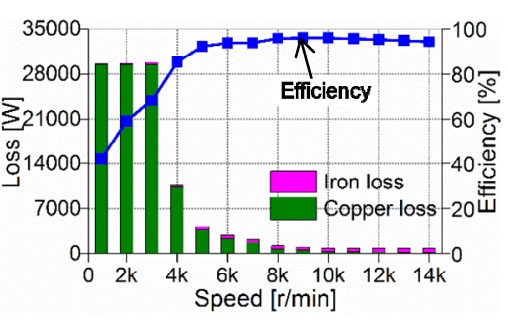

(c)

Fig. 14. Loss and efficiency versus speed: $I_{e m}=130 \mathrm{~A}(\mathrm{a}) ; I_{e m}=260 \mathrm{~A}(\mathrm{~b}) ; I_{e m}=390 \mathrm{~A}$ (c) 
As shown in Fig. 14(a), when the speed exceeds $4000 \mathrm{r} / \mathrm{min}$, the copper loss is signifycantly decreased by a field-weakening control strategy. Although the iron loss has been increased, the total loss is reduced, which leads to the efficiency of PMASynRM increased during flux weakening operation at high speed. The iron loss gradually increases with speed up to $4000 \mathrm{r} / \mathrm{min}$, as shown in Figs. 14(b) and (c). This is because the applied MTPA control is above $4000 \mathrm{r} / \mathrm{min}$. In the speed region from 4000 to $14000 \mathrm{r} / \mathrm{min}$, the current gradually decreases even if the current limit value $I_{e m}$ is set to 260 or $390 \mathrm{~A}$, and copper losses decreases with the increase of speed. The maximum efficiency is $95.6 \%$ at the speed of $7000 \mathrm{r} / \mathrm{min}$ when the rated current is $260 \mathrm{~A}$, which satisfies the target of the maximum efficiency.

\subsection{Efficiency map}

The efficiency maps of the proposed PMASynRM is shown in Fig. 15. $V_{e m}$ is set to $450 \mathrm{~V}$, and $I_{e m}$ is set to 130,260 and $390 \mathrm{~A}$. The maximum efficiency reaches to $95.8 \%, 96.6 \%$ and $96.9 \%$, when $I_{e m}$ is set to 130,260 and 390 A, respectively. The efficiency of PMASynRM is over $90 \%$ across a wide operating range, as shown in Figs. 15(a), (b) and (c). When the maximum phase current is $390 \mathrm{~A}$, the maximum efficiency is $96.9 \%$ and the maximum torque is $204.8 \mathrm{~N} \cdot \mathrm{m}$, which satisfies the target efficiency and the target maximum torque in Table 2.

(a)

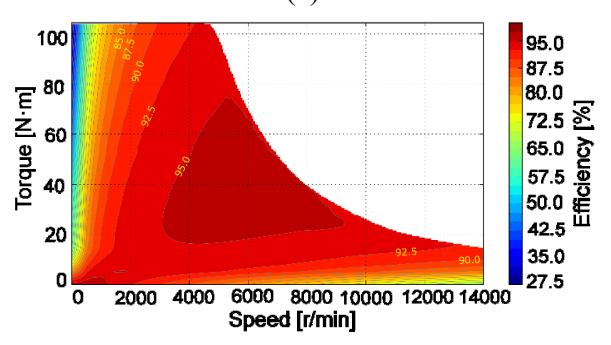

(b)

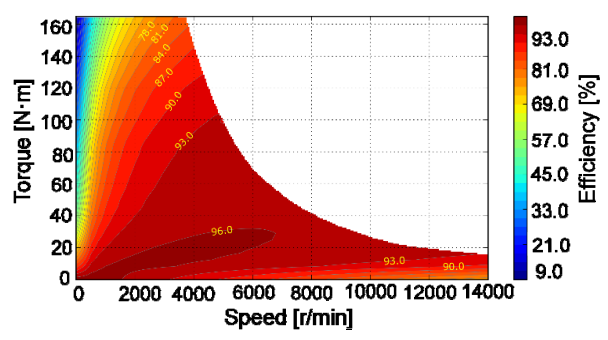

(c)

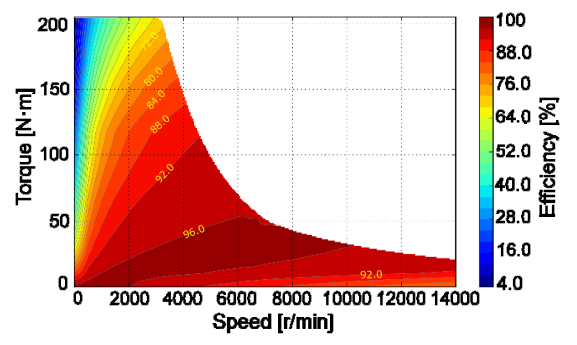

Fig. 15. Efficiency maps of the proposed PMASynRM: $I_{e m}=130 \mathrm{~A}$ (a); $I_{e m}=260 \mathrm{~A}$ (b); $I_{e m}=390 \mathrm{~A}$ (c)

\section{Compare to Prius 2010 IPMSM}

Some parameters of PMs were compared in Toyota Prius 2010 IPMSM and the proposed PMASynRM in Table 3, which includes PM dimensions, magnet volume, the maximum work- 
ing temperature, price and cost of PMs. It should be noted that the coercive force of N36_Z20 is about four times of Y30BH. However, the price of N36_Z20 is 4342.1¥ per kilogram, which caused that the total costs of PMs in Toyota Prius 2010 IPMSM are 116 times of the proposed PMASynRM. Furthermore, the maximum working temperature of ferrite magnets (Y30BH) is $460^{\circ} \mathrm{C}$, which is about two times of N36_Z20. Therefore, the proposed PMASynRM with low-cost ferrite magnets could meet high-power density, high torque density, high efficiency and a wide range speed operation, and a higher working environment temperature is obtained.

Table 3. Some parameter of PMs

\begin{tabular}{c|c|c}
\hline Parameter & $\begin{array}{c}\text { Toyota Prius2010 } \\
\text { IPMSM }\end{array}$ & $\begin{array}{c}\text { Proposed } \\
\text { PMASynRM }\end{array}$ \\
\hline PM material & N36_Z20 & Y30BH \\
\hline Coercive force of PM $(\mathrm{kA} / \mathrm{m})$ & 920 & 232 \\
\hline PM dimensions $(\mathrm{mm})$ & $49.3 \times 17.88 \times 7.16^{*}$ & arc-shaped \\
\hline Magnet volume $\left(\mathrm{cm}^{3}\right)$ & 100.98 & 262.08 \\
\hline Total mass of magnets $(\mathrm{kg})$ & 0.768 & 1.991 \\
\hline PM price** $(¥)$ & 4342.1 & 14.4 \\
\hline PM total cost $(¥)$ & 3334.7 & 28.7 \\
\hline Max. working temperature $\left({ }^{\circ} \mathrm{C}\right)$ & 200 & 460 \\
\hline
\end{tabular}

*One magnet **2016

\section{Conclusions}

The novel rotor structures of PMASynRM with ferrite magnets have been examined in this paper, which considered irreversible demagnetization, mechanical strength and torque ripple. In order to reduce the torque ripple, the asymmetric flux barrier was used in the rotor, and the torque ripple is less than $10 \%$ when $I_{e m}$ is 130,260 and 390 A. Some characteristics including the torque, output power, loss and efficiency were calculated by FEA. The maximum efficiency is $96.9 \%$ when adopting the maximum phase current, which satisfies the target efficiency of $95 \%$. Meanwhile, the high-power density and high torque density of PMASynRM are obtained compared to Prius 2010 IPMSM. It can be found that the torque, efficiency and operating speed-torque region of PMASynRM are competitive when applied in HEVs/EVs. However, its phase current is increased and the power factor is low, which needs further study or looking for new materials to replace the rare-earth PMs. A prototype of the proposed PMASynRM should be manufactured to validate the loss, maximum torque, output power, efficiency, and thermal analysis.

\section{Acknowledgements}

This work is supported by National Natural Science Foundation of P.R.China (No.51267006), Plan Project of Jiangxi Province of P.R.China (20151BBE50109, 20153BCB23012), Program of Qingjiang Excellent Young Talents (JXUST). 


\section{References}

[1] Jurkovic S., Rahman K.M., Savagian P.J., Design, Optimization and Development of Electric Ma chine for Traction Application in GM Battery Electric Vehicle, 2015 IEEE International Electric Machine \& Drives Conference (IEMDC), Coeur d'Alene, USA, pp. 1814-1819 (2015).

[2] Santiago J.D., Bernhoff H., Ekergard B., Eriksson S., Ferhatovic S., Waters R., Leijon M., Electrical Motor Drivelines in Commercial All-Electric Vehicles: A Review, IEEE Transactions Vehicular Technology, vol. 61, no. 2, pp. 475-484 (2012).

[3] Nerg J., Rilla M., Ruuskanen V., Pyrhonen J., Ruotsalainen S., Direct-Driven Interior Magnet Permanent-Magnet Synchronous Motors for a Full Electric Sports Car, IEEE Transactions Industrial Electronics, vol. 61, no. 8, pp. 4286-4294 (2014).

[4] Galioto S.J., Reddy P.B., EL-Refaie A.M., Alexander J. P., Effect of Magnet Types on Performance of High-Speed Spoke Interior-Permanent-Magnet Machines Designed for Traction Applications, IEEE Transactions on Industry Applications, vol. 51, no. 3, pp. 2148-2150 (2015).

[5] Abdel-Khalik A.S., Ahmed S., Massoud A.M., Effect of Multilayer Windings with Different Stator Winding Connections on Interior PM Machine for EV Applications, IEEE Transactions on Magnetics, vol. 52, no. 2, 8100807 (2016).

[6] Ding W., Hu Y., Wu L., Analysis and Development of Novel Three-Phase Hybrid Magnetic Paths Switched Reluctance Motors Using Modular and Segmental Structures for EV Applications, IEEE/ASME Transactions on Mechatronics, vol. 20, no. 5, pp. 3427-2451 (2015).

[7] Kiyota K., Kakishima T., Sugimoto H., Chiba A., Comparison of the Test Result and 3D-FEM Anlysis at the Knee Point of a $60 \mathrm{~kW}$ SRM for a HEV, IEEE Transactions on Magnetics, vol. 49, no. 5, pp. 2291-2294 (2013).

[8] Nezamabadi M.M., Afjei E., Torkaman H., Design, Dynamic Electromagnetic Analysis, FEM, and Fabrication a New Switched Reluctance Motor with Hybrid Motion, IEEE Transactions on Magnetics, vol. 52, no. 4, 8201708 (2016).

[9] Takeno M., Chiba A., Hoshi N., Ogasawara S., Takemoto M., Rahman M.A., Test Results and Torque Improvement of the 50-kW Switched Reluctance Motor Designed for Hybrid Electric Vehicles, IEEE Transactions on Industry Applications, vol. 48, no. 4, pp. 2874-2883 (2012).

[10] Chiba A., Takano Y., Takeno M., Imakama T., Hoshi N., Takemoto M., Ogasawara S., Torque Density and Efficiency Improvements of a Switched Reluctance Motor Without Rare-Earth Material for Hybrid Vehicles, IEEE Transactions on Industry Applications, vol. 47, no. 3, pp. 1240-1246 (2011).

[11] Kiyota K., Kakishima T., Chiba A., Rahaman M.A., Cylindrical Rotor Design for Acoustic Noise and Windage Loss Reduction in Switched Reluctance Motor for HEV Applications, IEEE Transactions on Industry Applications, vol. 52, no. 1, pp. 154-162 (2016).

[12] Bayless J., Kurihara N., Sugimoto H., Chiba A., Acoustic Noise Reduction of Switched Reluctance Motor with Reduced RMS Current and Enhanced Efficiency, IEEE Transactions on Energy Conversion, vol. 31, no. 2, pp. 1-10 (2015).

[13] Rasmussen P.O., Andreasen J.H., Pijanowski J.M., Structural Stator Spaces-A Solution for Noise Reduction of Switched Reluctance Motors, IEEE Transactions on Industry Applications, vol. 40, no. 2, pp. 574-561 (2004).

[14] Ooi S., Morimoto S., Sanada M., Inoue Y., Performance Evaluation of a High-Power-Density PMASynRM With Ferrite Magnets, IEEE Transactions on Industry Applications. vol. 49, no. 3, pp. 1308-1314 (2013).

[15] Obata M., Morimoto S., Sanada M., Inoue Y., Performance of PMASynRM With Ferrite Magnets for EV/HEV Applications Considering Productivity, IEEE Transactions on Industry Applications, vol. 50, no. 4, pp. 2427-2435 (2014).

[16] Morimoto S., Ooi S., Inoue Y., Sanada M., Experimental Evaluation of a Rare-Earth-Free PMASynRM With Ferrite Magnets for Automotive Applications, IEEE Transactions on Industrial Electronics, vol. 61, no. 10, pp. 5749-5756 (2014).

[17] Sanada M., Inoue Y., Morimoto S., Structure and Characteristics of High-Performance PMASynRM with Ferrite Magnets, Electrical Engineering in Japan, vol. 187, no. 1, pp. 42-50 (2014). 
[18] Cai H., Guan B., Xu L., Low-Cost Ferrite PM-Assisted Synchronous Reluctance Machines for Electric Vehicles, IEEE Transactions on Industrial Electronics, vol. 61, no. 10, pp. 5741-5748 (2014).

[19] Kim W.H., Kim K.S., Kim S.J., D. Kang W., Go S.C., Chun Y.D., Lee J., Optimal PM Design of PMASynRM for Wide Constant-Power Operation and Torque Ripple Reduction, IEEE Transactions on Magnetics, vol. 45, no. 10, pp. 4660-4663 (2009).

[20] Boldea I., Tutelea L., Pitic C.I., PM-Assisted Reluctance Synchronous Motor/Generator (PM-RSM) for Mild Hybrid Vehicles: Electromagnetic Design, IEEE Transactions on Industry Applications, vol. 40, no. 2, pp. 492-498 (2004).

[21] Kondo K., Kusase S., Maekawa T., Hanada K., A New PM-Assisted Synchronous Reluctance Motor With Three-Dimensional Trench Air Gap, IEEE Transactions on Industry Applications, vol. 50, no. 4, pp. 2485-2492 (2014).

[22] Bianchi N., Fornasiero E., Soong W., Selection of PM Flux Linkage for Maximum Low-Speed Torque Rating in a PM-Assisted Synchronous Reluctance Machine, IEEE Transactions on Industry Applications, vol. 51, no. 5, pp. 3600-3608 (2015).

[23] Chen X., Wang J., Lazari P., Chen L., Permanent Magnet Assisted Synchronous Reluctance Machine with Fractional-Slot Winding Configurations, 2013 IEEE International Electric Machine \& Drives Conference (IEMDC), Chicago, USA, pp. 374-381 (2013).

[24] Yamazaki K., Tamiya S., Utsuno K., Shima K., Fukami T., Sato M., Rotor Shape Optimization for Output Maximization of Permanent-Magnet-Assisted Synchronous Machines, IEEE Transactions on Industry Applications, vol. 51, no. 4, pp. 3077-3085 (2015).

[25] Carraro E., Morandin M., Bianchi N., Traction PMASR Motor Optimization According to a Given Driving Cycle, IEEE Transactions on Industry Applications, vol. 52, no. 1, pp. 209-216 (2016).

[26] Kim S.I., Park S., Park T., Cho J., Kim W., Lim S., Investigation and Experimental Verification of a Novel Spole-Type Ferrite-Magnet Motor for Electric-Vehicles Traction Drive Applications, IEEE Transactions on Industrial Electronics, vol. 61, no. 10, pp. 5763-5770 (2014).

[27] Barcaro M., Bianchi N., Magnussen F., Permanent-Magnet Optimization in Permane-MagnetAssisted Synchronous Reluctance Motor for a Wide Constant-Power Speed Range, IEEE Transactions on Industrial Electronics, vol. 59, no. 6, pp. 2495-2502 (2012).

[28] Lohninge R., Grabner H., Weidenhozer G., Silber S., Amrhein W., Modeling, Simulation, and Design a Permanent -Magnet-Assisted Synchronous Reluctance Machine, IEEE Transactions on Industry Applications, vol. 51, no. 1, pp. 196-203 (2015).

[29] Huang H., Hu Y., Xiao Y., Lyu H., Research of Parameters and Anti-demagnetization of RareEarth-Less Permanent Magnet-Assisted Synchronous Reluctance Motor, 2015 IEEE Magnetics Conference (INTERMAG), Beijing, China, 8112504, (2015).

[30] Vagati A., Boazzo B., Guglielmi P., Pellegrino G., Design of Ferrite-Assisted Synchronous Reluctance Machines Robust Toward Demagnetization, IEEE Transactions on Industry Applications, vol. 50, no. 3, pp. 1768-1779 (2014).

[31] Sanada M., Inoue Y., Morimoto S., Rotor Structure for Reducing Demagnetization of Magnet in a PMASynRM with Ferrite Permanent Magnet and its Characteristics, 2011 IEEE Energy Conversion Congress and Exposition (ECCE), Phoenix, AZ, pp. 4189-4194 (2011).

[32] Barcaro M., Meneghetti G., Bianchi N., Structural Analysis of the Interior PM Rotor Considering Both Static and Fatigue Loading, IEEE Transactions on Industry Applications, vol. 50, no. 1, pp. 253-260 (2014).

[33] Kiyota K., Chiba A., Design of Switched Reluctance Motor Competitive to 60-Kw IPMSM in ThirdGeneration Hybrid Electric Vehicle, IEEE Transactions on Industry Applications, vol. 48, no. 6, pp. 2303-2309 (2012).

[34] Urase K., Yabu N., Kiyota K., Sugimoto H., Chiba A., Takemoto M., Ogasawara S., Hoshi N., Energy Efficiency of SR and IPM Generators for Hybrid Electric Vehicle, IEEE Transactions on Industry Applications, vol. 51, no. 4, pp. 2874-2883 (2015).

[35] Boldea I., Tutalea L.N., Parsa L., Dorrell D., Automotive Electric Propulsion Systems With Reduced or No Permanent Magnets: An Overview, IEEE Transactions on Industrial Electronics, vol. 61 , no. 10 , pp. 5696-5711 (2014). 
[36] Ren W., Xu Q., Li Q., Chen L., Reducing Cogging Torque and Suppressing Torque Ripple in PMASynRM for EV/HEV Applications, Transportation Electrification Asia-Pacific (ITEC AsiaPacific), 2014 IEEE Conference and Expo., Beijing, China, pp. 1-6 (2014).

[37] Wang K., Zhu Z.Q., Ombach G., Koch M., Zhang S., Xu J., Torque ripple reduction of synchronous reluctance machines: using asymmetric flux-barrier, COMPEL: The International Journal for Computation an Mathematics in Electrical and Electronic Engineering, vol. 34, no. 1, pp. 18-31 (2015).

[38] Sanada M., Hiramoto K., Morimoto S., Takeda Y., Torque Ripple Improvement for Synchronous Reluctance Motor Using an Asymmetric Flux Barrier Arrangement, IEEE Transactions on Industry Applications, vol. 40, no. 4, pp. 1076-1082 (2004).

[39] Pina A.J., Xu L., Modeling of Synchronous Reluctance Motors Aided by Permanent Magnets with Asymmetric Rotor Poles, 2015 IEEE International Electric Machine \& Drives Conference (IEMDC), Coeur d'Alene, USA, pp. 412-418 (2015)

[40] Bianchi N., Bolognani S., Bon D., Pre M.D., Rotor Flux-Barrier Design for Torque Ripple Reduction in Synchronous Reluctance and PM-Assisted Synchronous Reluctance Motors, IEEE Transactions on Industry Applications, vol. 45, no. 3, pp. 921-927 (2009). 